\title{
CYBERAGGRESSION: THE EFFECT OF PARENTAL MONITORING ON BYSTANDER ROLES
}

\author{
Michal Levy and Revital Sela-Shayovitz
}

\begin{abstract}
The digital world has created new opportunities for aggression through cyberaggression. Despite growing research interest in cyberaggression, little is known about the various bystander roles in the digital interaction. This paper examines the effect of parental monitoring practices (parental restriction, youth disclosure, and parental solicitation) on five bystander roles: aggressor-supporter, defender, help-seeker, outsider, and passive bystander. Data were derived from self-report questionnaires answered by a sample of 501 adolescents in Israel. The findings indicate that adolescents who share their experiences of cyberaggression with their parents are more likely than others to defend the cybervictim. Interaction effects were found between adolescent gender, installing warning applications, parent gender, and the aggressor-supporter role. Boys whose parents installed warning applications and whose fathers monitored their online activities were positively associated with the aggressor-supporter role, while girls who were higher aggressor-supporter reported that their parents used warning applications but did not monitor their online activities. The discussion focuses on the theoretical and practical implications of the effectiveness of parental monitoring on the cyberaggression bystander's role.
\end{abstract}

Keywords: cyberaggression, bystander roles, aggressor supporter, defender, helpseeker, passive bystander, parental involvement

Michal Levy PhD (corresponding author) teaches Special-Education at David-Yellin college and at the Seymour Fox School of Education, Hebrew University of Jerusalem, Mount Scopus Campus, Jerusalem 919050, Israel. Email: michal.levy3@mail.huji.ac.il

Revital Sela-Shayovitz $\mathrm{PhD}$ is a Professor in the Faculty of Humanities and Social Sciences, Ono Academic College, Tzahal St 104, Kiryat Ono, Israel. Email: revital.s@ono.ac.il 
Communication technologies have become a necessity of daily life. Adolescents, sometimes referred to as the "net generation" or "digital natives", frequently use online social networks; one survey of American adolescents showed that a large majority (95\%) have access to smartphones and $45 \%$ of them used the Internet "almost constantly" (Anderson \& Jiang, 2018, p. 2). At the same time, the digital world has created new opportunities for delinquency and crime (Vandebosch et al., 2012), including acts of aggression that negatively affect many adolescents. For example, adolescents who are either cyberaggressors or cybervictims are more likely to have suicidal thoughts and to attempt suicide than are adolescents who have not experienced cyberaggression (Patchin \& Hinduja, 2010). Accordingly, cyberaggression has become a growing concern for society: one extensive literature survey found prevalence rates in adolescents ranging from 5.3\% to $31.5 \%$ for cyberaggression, and $2.2 \%$ to $56.2 \%$ for cybervictimization (Modecki et al., 2014).

Social ecological theory (Bronfenbrenner, 1992) emphasizes the need to explore the interrelated systems, both proximal and distal with respect to the children themselves, that influence children's behavior; these are known as micro-, meso-, exo-, macro-, and chronosystems. As described by Hong and Espelage (2012), the theory provides a framework for understanding potential risk and protective factors deriving from different systems, whether individual (e.g., age, gender), social (e.g., family relations, peer group dynamics), or environmental (e.g., cultural norms, religion). Parental monitoring is one example of a proximal effect that is situated in the micro-system; it incorporates interactions of youth with others and with groups within immediate settings (e.g., home, school), and influences adolescent cyberaggression involvement (Baldry et al., 2019).

While there is accumulated knowledge about parental monitoring in the case of cyberaggressors, cybervictims, and cyberaggressor-victims (Khurana et al., 2015; Kowalski et al., 2014; Mishna et al., 2012), little is known about the effect of parental monitoring on cyberbystander roles (Wright \& Wachs, 2018). The current study seeks to address this research gap by exploring the effect of parental monitoring on cyberbystander roles and how the interactions of parental monitoring with individual characteristics (adolescent age and gender, and parent gender) affect these roles. We posit that it is particularly important to investigate parental monitoring: although cyberbystanders may be motivated to assist when witnessing prolonged damage to cybervictims on a daily basis, it can be difficult for them to defend the victim and help stop the attacks without adult supervision or intervention (Kowalski et al., 2014).

We first review the literature on cyberaggression and bystander involvement in aggression and cyberaggression. We then address the existing literature regarding parental monitoring in cyberaggression, taking into account gender and age differences. 
International Journal of Child, Youth and Family Studies (2020) 11(4.2): 13-36

\section{Cyberaggression}

Cyberaggression refers to a wide range of negative behaviors that occur in internet settings. These behaviors include publishing offensive private pictures and videos and posting or sending malicious messages, as well as other forms of aggressive behavior such as "flaming" (harsh invective), impersonation, and cyberstalking (Grigg, 2010). Recent indications show that cyberaggression occurs less frequently than traditional aggression (Wang et al., 2011); however, the psychosocial outcomes of cyberaggression (stress, anxiety, depression, dropping out of school, substance abuse, and, in extreme cases, murder and suicidal ideation) are consequential (Kowalski et al., 2014).

Aggression, whether traditional or cyber, may be more than a dyadic interaction between an aggressor and a victim: group processes and bystanders are often involved. Thus, when cyberaggression takes place in a peer group, its members engage in different roles, such as encouraging the aggressor, defending the victim, or remaining passive and refraining from any involvement (Salmivalli, 2010; Salmivalli \& Voeten, 2004).

Extensive research has been conducted on bystander roles in traditional aggression incidents (Salmivalli \& Voeten, 2004; Thornberg \& Jungert, 2013). Bystanders play a vital role in determining the outcomes of aggression incidents (Salmivalli, 2010). In Atlas and Pepler's (1998) study of classroom bullying, bystanders were present in $85 \%$ of the incidents observed. Hawkins et al. (2001) found that peers in a school playground intervened in $19 \%$ of bullying incidents, and succeeded in stopping $57 \%$ of those.

Salmivalli (2010) distinguished three main bystander behavior roles: pro-aggressor (reinforcer and assistant, referred to here as aggressor-supporter), in which the individual encourages and actively supports the aggressor; pro-victim (defender), in which the bystander actively helps the victim and opposes the aggressor; and passive (outsider), in which the bystander avoids active involvement and does not extend support to either side. A recent study identified two additional discrete roles - help-seeker and passive bystander; empirical distinctions have been found between help-seekers and defenders, as well as between outsiders and passive bystanders (Levy \& Gumpel, 2018).

The three main bystander roles (aggressor-supporter, defender, and outsider) also appear in cyberaggression incidents (Bastiaensens et al., 2014). However, Barlinska and colleagues (2013) found that most bystanders support the cyberaggressor or remain outsiders, whereas cyberdefenders are portrayed as exceptional bystanders who intervene on behalf of the victim because they have experienced cybervictimization and possess moral reasoning skills (Patterson et al., 2017). Olenik-Shemesh and colleagues (2017) reported that $46.4 \%$ of participants in a sample of Israeli youth had been cyberaggression bystanders. More than half had taken the passive role; only one third had actively helped the cybervictim. 
International Journal of Child, Youth and Family Studies (2020) 11(4.2): 13-36

Characteristics of cyberaggression, but not of aggression generally, include anonymity, low supervision, physical distance, and public exposure (Patchin \& Hinduja, 2010). These characteristics may make it difficult for cyberbystanders to intervene in cyberaggression incidents. For example, in traditional aggression the passive bystander implicitly approves of or consents to the aggressor's behavior by witnessing the event without intervening (Salmivalli, 2010). In cyberaggression, the victim may actually prefer that bystanders remain passive, since the involvement of further individuals carries the risk of increasing public exposure and thus escalating the harmful act (Barlińska et al., 2013). At the same time, physical distance can be considered a disadvantage for bystanders because online interactions are often not enriched by nonverbal social cues such as facial expressions that could otherwise enable them to recognize the victim's distress. Conversely, physical distance may help bystanders support the victim without fear of risking physical retaliation by the aggressor (DeSmet et al., 2016).

A wide range of factors determine bystander decisions to intervene online, including: age and gender (Olenik-Shemesh et al., 2017), incident severity, social pressure (Bastiaensens et al., 2016), moral disengagement (DeSmet et al., 2014; Patterson et al., 2017), affective and cognitive empathy (Barlińska et al., 2013), number of offenders (Kazerooni et al., 2018), and the bystander effect (Obermaier et al., 2016). However, little research has examined the effect of parental monitoring on cyberbystander roles.

\section{Parental Monitoring}

Family connections become less pronounced in adolescence, with social ties and status among peers taking precedence, especially among early adolescents (Boniel-Nissim \& Sasson, 2018). While striving to gain more independence, they reduce the frequency and intensity of communication with their parents (Keijsers \& Poulin, 2013). They begin to take control over the amount of information they share with their parents by not revealing thoughts and experiences as freely as in the past (Frijns et al., 2020). In an attempt to regain control, parents may monitor or restrict the adolescent's activities, or explicitly solicit information from them (Laird et al., 2013).

Some terms used to describe parental involvement in adolescents' cyberexperiences are "parental control", "parental monitoring", and "parental mediation". Parental control refers to parental awareness and follow-up of the adolescent's social connections and activities (Elsaesser et al., 2017). Kerr and colleagues (2010) describe three parental monitoring strategies that help parents obtain information about the whereabouts of their adolescent children: (a) control, or restriction, whereby parents set rules and demand information from adolescents before they engage in social activities; (b) parental solicitation, which refers to requesting information from the adolescent, and his or her friends and their parents; and (c) youth disclosure, which depends on adolescents' willingness to proactively share information with parents about their social activities. The first two strategies are initiated by parents and the third by adolescents themselves. Some scholars (e.g., Mesch, 2009) who use the term "parental mediation" distinguish between restriction mediation, by which parents either limit the adolescent's access to social media or monitor their 
online habits by installing warning applications, and evaluation mediation, which relates to parent's tendency to openly discuss with their children the dangers to be found online (e.g., formulating together acceptable rules for web engagement).

For the purposes of this study we use the three parental monitoring strategies described by Kerr and colleagues (2010): parental restriction, youth disclosure, and parental solicitation.

Findings regarding the effects of parental monitoring on reducing cyberaggression are inconsistent. For example, several studies have indicated that parental monitoring reduces children's aggressive behavior on the internet (Khurana et al., 2015; Shapka \& Law, 2013), while others did not find such an association (Mesch, 2009; Sengupta \& Chaudhuri, 2011). Khurana et al. (2015) found an indirect association between parental monitoring and cyberaggression, mediated by restricting internet access in the child's bedroom. Several studies found the effect of parental monitoring to be dependent on the type of participation in cyberaggression. Mishna and colleagues (2012) found that parents of children who were both cyberaggressors and cybervictims (cyberaggressor-victims) were more likely to use internet blocking programs than parents of children who were not involved in either cyberaggression or cybervictimization. Cyberaggressors who reported weaker emotional relationships with their parents were more severely disciplined by their parents, and their online activities were less closely monitored (Wang et al., 2009). Similarly, cybervictims reported less parental control over their online activities (Kowalski et al., 2014).

Although there is growing knowledge about parental monitoring in cyberaggression, much less is known about the role of youth disclosure. Early adolescents are reluctant to disclose information to their parents (Laird et al., 2013). Makri-Botsari and Karagianni (2014) indicated that the majority of adolescents in their study preferred to report cyberaggression incidents to their friends rather than to their parents. They also suggested that adolescents who more often engaged in cyberaggression against peers were compensating for lack of communication with and rejection by their parents.

Although adolescents are often reluctant to disclose information about their cyberactivities, some evidence indicates that adolescent disclosure is more effective than parental monitoring in reducing delinquency. In a longitudinal study on the associations between three parental strategies - control, solicitation, and reliance on youth disclosure - and delinquency among adolescents, parental knowledge of an adolescent's whereabouts was associated with the adolescent's disclosure of information and not with parental control; only disclosure predicted decreased delinquency (Kerr et al., 2010). Disclosure was also found to be protective against aggression and cyberaggression (Elsaesser et al., 2017) and should therefore be included in studies on cyberbystander roles.

When parents react supportively to disclosure of bystander cyberexperiences, adolescents' confidence about intervening on behalf of a victim may increase: findings have indicated that higher levels of social support and lower levels of loneliness among cyberbystanders are associated 
with extending help to the victim (Olenik-Shemesh et al., 2017). Hence, adolescent disclosure may be crucial in determining whether a particular adolescent will provide help and support to the cybervictim. Despite growing empirical data regarding the effect of parental monitoring on cyberaggression, research on the effects of disclosure on cyberbystander roles is limited. DeSmet and colleagues (2014) showed that adolescents generally perceived a lack of parental support for defending the victim. Wright and Wachs (2018) found that being a bystander who witnessed cyberaggression was positively related to both restriction and evaluation mediation. However, these results were limited to witnessing the cyberaggression, and did not distinguish among bystander roles.

\section{Gender and Age Differences in Cyberaggression, Cyberbystander Roles, and Application of Parental Monitoring}

Findings regarding gender and age differences in cyberbystander behavior have been inconclusive (Hinduja \& Patchin, 2010). Some studies did not find gender and age differences in cyberbystander roles (Barlińska et al., 2013; Macháčková et al., 2013), whereas others found such differences to exist. For example, various studies found that younger adolescent girls helped victims, while boys and older adolescents joined the aggressor or remained passive (Pabian \& Vandebosch, 2016; Van Cleemput et al., 2014). In contrast, Olenik-Shemesh and colleagues (2017) reported that girls and older adolescents were more likely to actively help cybervictims than to remain passive bystanders. Bastiaensens and colleagues (2014) showed results similar to traditional aggression, with girls tending to comfort and support the victim and boys tending to support the aggressor.

Past research demonstrated that in cases of cyberaggression and cybervictimization, parental monitoring differed by adolescent age (Khurana et al., 2015) and gender (Wright, 2017). In relation to gender differences, Baldry and colleagues (2019) showed that boys who were cyberaggressors did not receive parental guidance regarding safe internet use and the risks of online surfing; in contrast, girls who suffered cybervictimization reported elevated parental supervision. Keijsers and Poulin (2013) examined changes in parent-adolescent communication patterns among 390 adolescents aged 12 to 19 . Early adolescents reported less disclosure of information and early adolescent girls reported less parental solicitation and higher secrecy levels. Middle adolescents reported less parental monitoring and middle adolescent girls reported more adolescent disclosure and parental solicitation and less keeping of secrets. These results underscore the need to explore the impact of parental monitoring on cyberbystander roles in relation to adolescent gender and age.

The role of parent gender is another important aspect of parental monitoring. Inconsistent findings have emerged regarding the effects of parent gender on parental monitoring with regard to cyberaggression. Several studies have found that fathers are more engaged than mothers in internet monitoring (Wang et al., 2005), while others have indicated stronger involvement of mothers in parental control and parental warmth (Lau \& Yuen, 2016; Valcke et al., 2010). Some consistency was found, however, regarding parental styles in relation to cyberaggression, with 
fathers having a more dominant, authoritarian, style and mothers an authoritative parenting style (Valcke et al., 2010). A longitudinal study conducted by Zurcher and colleagues (2018) demonstrated different parental styles with respect to cyberaggression by both adolescent and parent gender. Both parental verbal hostility and physical coercion (subtypes of the authoritarian parenting style) were linked to cyberaggression attitudes and participation among boys, while a mother's permissive parental style was linked to cyberaggression among girls. Research is lacking regarding whether the effects of parental monitoring on cyberbystander roles vary according to parent gender.

In summary, examining the effects of parental monitoring on cyberbystander roles in relation to adolescent gender and age and parent gender may enhance our understanding of familial and demographic patterns underlying cyberbystander roles.

\section{Research Aims and Hypotheses}

The present study aimed to fill the literature gap by exploring the effect of parental monitoring on cyberbystander roles in relation to gender and age differences. Specifically, the first aim was to determine whether the help-seeker and passive-bystander roles are found in cyberaggression interactions. We assumed that, similar to the bystander roles in traditional aggression (Levy \& Gumpel, 2018), five bystander roles would emerge in cyberaggression: aggressor-supporter, defender, help-seeker, outsider, and passive bystander (H1).

The second aim was to examine the main effects of parental monitoring (parental solicitation, parental restriction, and youth disclosure) on cyberbystander roles. We anticipated that cyber helpseekers and defenders would share their digital experiences with their parents more often than aggressor-supporters and passive bystanders, while the latter groups would report having warning and blocking applications installed on their computers and mobile devices more often than other bystanders (H2). We also assumed that adolescents whose parents discuss online dangers and ask for information regarding online habits would defend the cybervictim, while adolescents whose parents set rules would support the cyberaggressor $(\mathrm{H} 3)$.

The third aim was to evaluate to what extent cyberbystander roles differ in interactions between parental monitoring variables (restriction, disclosure, and solicitation) and demographic variables (adolescent gender and age, and parent gender). We assumed that older adolescent girls who share their cyberexperiences with their mothers would defend the victim more often than younger adolescents, whereas boys whose fathers monitor their online habits with restrictive measures and by setting rules would more often support the cyberaggressor $(\mathrm{H} 4)$. 
International Journal of Child, Youth and Family Studies (2020) 11(4.2): 13-36

\section{Method}

\section{Participants}

The sample consisted of 501 adolescents in Israel, all students in the 8th to 12th grades. Girls constituted more than half the sample (65.9\%) and boys 34.1\%. Participant age ranged from 14 to 18 years $(M=16.31, S D=1.34)$. More participants were in 12 th grade $(45.1 \%)$ than any other grade; the fewest were in 8 th grade $(4.8 \%)$.

\section{Procedure}

Data were collected using an anonymous self-report questionnaire in Hebrew that was sent to the student's email address and contained a web link. Sampling was conducted after receiving the permission of the Ono Academic College ethics committee and the active consent of the participant's parents. Participants could discontinue their participation at any time, were ensured anonymity, and received a gift card for their participation.

\section{Assessments and Variables}

Dependent variables: The cyberbystander roles scale was based on the Participant Role Scale (revised version; Salmivalli \& Voeten, 2004), using the Hebrew version of the self-report questionnaire (Levy \& Gumpel, 2018). The questionnaire was adjusted to cyberaggression incidents. Participants were asked to think of cyberaggression incidents in the past 6 months and to select the responses that most characterized them. The questionnaire included 15 items that describe cyberbystander roles in cyberaggression: defender (e.g., "You sent messages to others in order to help the victim"); aggressor-supporter (e.g., "You encouraged the offenders by sending comments"); help-seeker (e.g., "You notified an adult [parent, teacher, principal, or counselor] about cybervictim abuse"); passive bystander (e.g., "You read the offensive messages sent to the cybervictim, but did not respond"); and outsider (e.g., "You do not come across cyberaggression situations"). Items were rated on a 5-point scale ranging from 1 (never) to 5 (always).

Independent Variables: The present study examined three main parental monitoring practices: parental solicitation, parental restriction, and youth disclosure. Parental solicitation was measured using three variables: discussion ("How often do your parents discuss social media dangers with you?"); information ("How often do your parents ask for information about your online surfing behavior?"); and rule-setting ("To what extent do your parents set rules and boundaries regarding your social media habits?"). Discussion and information were measured using a 3-point scale: 1 (never), 2 (seldom), 3 (frequently). Rule-setting was measured using a 3point scale: 1 (very little), 2 (moderately), 3 (very much). Parental restriction was measured using two variables: warning ("Have your parents installed warning applications on your mobile phone that warn of offensive content on social media?"), and blocking ("Have your parents blocked your access to certain websites?"). Youth disclosure was measured with respect to sharing information with their parents ("Do you share cyberaggression incidents with your parents?"). Parental restriction and youth disclosure variables were measured using two values: 1 (yes) and 2 (no). Two 
International Journal of Child, Youth and Family Studies (2020) 11(4.2): 13-36

variables examined parent gender: "Which parent monitors?", and "With which parent do adolescents share their online experiences?". These two variables were measured using 4 values: 1 (father), 2 (mother), 3 (both equally), 4 (neither).

Demographic variables: Participant demographic variables included gender and age. Gender consisted of 2 values: 1 (boy), 2 ( irl). Age included 5 values, ranging from 1 (14 years old) to 5 (18 years old).

\section{Data Analysis}

Data were collected using the participants' self-report responses and analyzed at three levels. First, an exploratory and confirmatory analysis was conducted to examine the number and type of cyberbystander roles and to determine whether help-seeker and passive-bystander roles are found in cyberaggression incidents (Aim 1). Exploratory factor analysis was conducted to understand the latent constructs underlying the observed cyberbystander variables. Confirmatory factor analysis was conducted to evaluate the hypothesized structures of the latent constructs (Bandalos \& Finney, 2018). Second, descriptive statistics were evaluated by dichotomizing the cyberbystander roles into "no-participation" and "participation" values based on the cutoff value of one standard deviation. Three multivariate regression analyses were then conducted to examine which parental monitoring practices explained the variance in each of the cyberbystander roles (Aim 2). Based on the Bonferroni correction that controls for Type I errors, the significance level was adjusted to .02 (.05 / 3). Standardized scores of the three parental solicitation variables were used in the multivariate regression analyses to control for different metrics. Last, ANOVA analyses were conducted to explore the interaction effects of parental restriction (warning and blocking) and youth disclosure (sharing) with demographic factors (gender and age) and parent gender (which parent monitors, and with which parent do adolescents share their online experiences) on each of the cyberbystander roles (Aim 3).

\section{Results}

\section{Bystander Role: Links to Gender, Age, and Parental Monitoring}

The results show that $45 \%(n=225)$ of the 501 participants were cyberaggression bystanders. Among the bystander roles, $10.8 \%(n=54)$ were aggressor-supporters, $18.2 \%(n=91)$ passive bystanders, and $16.0 \%(n=80)$ defenders. Descriptive statistics of the independent variables show that more girls than boys engaged in passive-bystander behavior (10.6\% and $7.6 \%$, respectively) and in defending the victim (11.0\% and 5.0\%, respectively). By contrast, more boys $(6.2 \%)$ than girls $(4.6 \%)$ supported the aggressor.

Regarding parental monitoring, 47.9\% $(n=240)$ of the participants shared their cyberaggression experiences with their parents, and 52.1\% $(n=261)$ did not do so. Most parents did not install a warning application on their children's mobile devices ( $88.8 \%, n=445)$, and many of them did not block their children's access to websites $(76.8 \%, n=385)$. Table 1 presents 
International Journal of Child, Youth and Family Studies (2020) 11(4.2): 13-36

averages, standard deviation, and Pearson correlation coefficients between cyberbystander roles and parental monitoring variables.

\section{Validation of Bystander Roles (Aim 1)}

The cyberbystander scale was validated using a combination of exploratory factor analysis (EFA) and confirmatory factor analysis (CFA). The maximum rotation likelihood extracted a three-factor solution. One item ("You usually do not encounter situations of cyberaggression") did not load on any factor and was therefore deleted. Three cyberbystander roles were found in online aggression: aggressor-supporter, defender, and passive bystander. The aggressor-supporter factor included one item ("You spread offensive messages or images of the aggressor to avenge what he or she did to the victim") worded to reflect the defender role. This item was also excluded from the study to prevent ambiguity. The three factors accounted for $56.89 \%$ of the variance. Based on the EFA, the model was then examined using CFA. The CFA results showed that all items loaded strongly on all four target factors $(\geq .50)$. The $\chi^{2 / \mathrm{df}}$ ratio was 3.63 and the RMSEA value was 0.07. The comparative fit index (CFI; .93), normed fit index (NFI; .90), and the Tucker-Lewis index (TLI: .91) values approached a good fit to the sample data. Appendix 1 summarizes the EFA and CFA analyses. The internal reliability of the defender, passive-bystander, and aggressor-supporter roles was measured using Cronbach's alpha and their values were $.87, .56$, and .86 respectively.

\section{The Effect of Parental Monitoring on Cyberbystander Roles (Aim 2)}

The results of the first regression analysis indicated that the first model explained $0 \%$ of the variance in the defender role $\left(R^{2}=.00, F(2,498)=.35, p>.05\right)$. The second model significantly added to the predictive equation $\left(R^{2}=.03, \Delta R^{2}=.03, p<.01, F(5,495)=3.12, p<.01\right)$, as did the third model $\left(R^{2}=.09, \Delta R^{2}=.06, p<.001, F(8,492)=6.39, p<.001\right)$. In the third model, both sharing $\left(\beta^{\mathrm{c}}=-.23, p<.001\right)$ and warning applications $\left(\beta^{\mathrm{c}}=-.13, p<.01\right)$ significantly explained the variance in the defender role.

A second regression analysis was conducted to examine whether parental monitoring (parental restriction, parental solicitation, and youth disclosure) predicted the aggressor-supporter role. Results indicated that the first model explained $3 \%$ of the variance $\left(R^{2}=.03, F(2,498)=7.62, p<\right.$ $.01)$. The second model significantly accounted for additional variance $\left(R^{2}=.05, \Delta R^{2}=.02, p<\right.$ $.01, F(5,495)=5.48, p<.001)$ as did the third model $\left(R^{2}=.14, \Delta R^{2}=.09, p<.001, F(8,492)=\right.$ $10.08, p<.001)$. Furthermore, rule-setting $\left(\beta^{\mathrm{b}}=.16, p<.01\right)$, warning applications $\left(\beta^{\mathrm{c}}=-.25, p<\right.$ $.001)$ and gender $\left(\beta^{\mathrm{a}}=-.17, p<.001 ; \beta^{\mathrm{b}}=-.15, p<.01 ; \beta^{\mathrm{c}}=-.13, p<.01\right)$ all significantly explained the variance in the aggressor-supporter role. 
International Journal of Child, Youth and Family Studies (2020) 11(4.2): 13-36

Table 1. Averages, Standard Deviations, and Pearson Correlation Coefficients Between Cyberbystander Roles and Parental Monitoring Variables

\begin{tabular}{|c|c|c|c|c|c|c|c|c|c|c|}
\hline Variable & $M$ & $S D$ & Defender & $\begin{array}{c}\text { Passive } \\
\text { bystander }\end{array}$ & $\begin{array}{l}\text { Aggressor- } \\
\text { supporter }\end{array}$ & Sharing & $\begin{array}{c}\text { Warning } \\
\text { app }\end{array}$ & $\begin{array}{c}\text { Blocks on } \\
\text { websites/ } \\
\text { apps }\end{array}$ & $\begin{array}{l}\text { Parents } \\
\text { discuss } \\
\text { dangers }\end{array}$ & $\begin{array}{c}\text { Parents } \\
\text { request } \\
\text { info }\end{array}$ \\
\hline Defender & 2.25 & .94 & - & & & & & & & \\
\hline Passive bystander & 2.30 & .90 & -.02 & - & & & & & & \\
\hline Aggressor-supporter & 1.25 & .58 & $.23^{* * *}$ & $.24^{* * *}$ & - & & & & & \\
\hline Sharing (youth disclosure) & 1.52 & .50 & $-.27^{* * *}$ & .08 & -.08 & - & & & & \\
\hline Warning applications & 1.89 & .32 & $-.15^{* *}$ & -.04 & $-.33^{* * *}$ & $.12^{* *}$ & - & & & \\
\hline Blocks on websites/applications & 1.77 & .42 & -.04 & .04 & $-.24^{* * *}$ & .00 & $.44^{* * *}$ & - & & \\
\hline Parents discuss online dangers & 2.15 & .68 & $.14^{* * *}$ & -.03 & .04 & $-.30^{* * * *}$ & $-.10^{*}$ & $-.12^{* *}$ & - & \\
\hline Parents request information & 1.75 & .70 & $.14^{* *}$ & .05 & .05 & $-.27^{* * *}$ & $-.15^{* *}$ & $-.14^{* *}$ & $.45^{* * *}$ & - \\
\hline Parents set online activity rules & 1.54 & .70 & .09 & .02 & $.17^{* * *}$ & $-.16^{* * *}$ & $-.26^{* * *}$ & $-.38^{* * *}$ & $.29^{* * *}$ & $.45^{* * *}$ \\
\hline
\end{tabular}

$* p<.05 . * * p<.01 . * * * p<.001$.

Table 2 presents the results of the regression model coefficients for the aggressor-supporter, defender, and passive-bystander roles. 
International Journal of Child, Youth and Family Studies (2020) 11(4.2): 13-36

Table 2. Multiple Regression Analyses for Aggressor-Supporter, Defender, and Passive-Bystander Roles

\begin{tabular}{|c|c|c|c|c|c|c|c|c|c|c|c|c|c|c|}
\hline & \multicolumn{4}{|c|}{ Model 1} & \multicolumn{5}{|c|}{ Model 2} & \multicolumn{5}{|c|}{ Model 3} \\
\hline & $\mathrm{B}$ & $S E$ B & $\beta^{\mathrm{a}}$ & $R^{2}$ & $\mathrm{~B}$ & $S E \mathrm{~B}$ & $\beta^{\mathrm{b}}$ & $R^{2}$ & $\Delta R^{2}$ & $\mathrm{~B}$ & $S E$ B & $\beta^{\mathrm{c}}$ & $R^{2}$ & $\Delta R^{2}$ \\
\hline Defender & & & & .00 & & & & $.03 * *$ & $.03 * *$ & & & & $.09 * * *$ & $.06 * * *$ \\
\hline Gender & .07 & .09 & .04 & & .08 & .09 & .04 & & & .07 & .09 & .04 & & \\
\hline Age & .01 & .03 & .01 & & .03 & .03 & .04 & & & .03 & .03 & .04 & & \\
\hline Parents discuss online dangers & & & & & .09 & .05 & .10 & & & .04 & .05 & .05 & & \\
\hline Parents request information & & & & & .09 & .05 & .09 & & & .04 & .05 & .05 & & \\
\hline Parents set online activity rules & & & & & .03 & .05 & .03 & & & .01 & .05 & .01 & & \\
\hline Sharing (youth disclosure) & & & & & & & & & & -.43 & .09 & - & & \\
\hline Warning applications & & & & & & & & & & -.38 & .15 & $-.13 * *$ & & \\
\hline Blocks on websites/applications & & & & & & & & & & .07 & .11 & .03 & & \\
\hline Aggressor-supporter & & & & $.03 * *$ & & & & $.05 * * *$ & $.02 * *$ & & & & $.14 * * *$ & $.09 * * *$ \\
\hline Gender & -.21 & .05 & - & & -.19 & .05 & $-.15 * *$ & & & -.15 & .05 & $-.13 * *$ & & \\
\hline Age & -.01 & .02 & -.03 & & -.01 & .02 & -.02 & & & -.01 & .02 & -.03 & & \\
\hline Parents discuss online dangers & & & & & -.00 & .03 & -.01 & & & -.01 & .03 & -.02 & & \\
\hline Parents request information & & & & & -.01 & .03 & -.02 & & & -.02 & .03 & -.04 & & \\
\hline Parents set online activity rules & & & & & .09 & .03 & $.16^{* *}$ & & & .04 & .03 & .06 & & \\
\hline Sharing (youth disclosure) & & & & & & & & & & -.08 & .05 & -.07 & & \\
\hline Warning applications & & & & & & & & & & -.45 & .09 & - & & \\
\hline Blocks on websites/applications & & & & & & & & & & -.15 & .07 & $-.11 *$ & & \\
\hline Passive bystander & & & & .01 & & & & .02 & .01 & & & & .03 & .01 \\
\hline Gender & -.20 & .09 & -.10 & & -.20 & .09 & -.11 & & & -.17 & .09 & -.09 & & \\
\hline Age & .02 & .03 & .02 & & .02 & .02 & .03 & & & .02 & .03 & .02 & & \\
\hline Parents discuss online dangers & & & & & -.06 & .05 & -.07 & & & -.04 & .05 & -.05 & & \\
\hline Parents request information & & & & & .08 & .05 & .09 & & & .09 & .05 & .10 & & \\
\hline Parents set online activity rules & & & & & -.01 & .05 & -.02 & & & .01 & .05 & .01 & & \\
\hline Sharing (youth disclosure) & & - & & & & & & & & .16 & .09 & .09 & & \\
\hline Warning applications & & & & & & & & & & -.17 & .15 & -.06 & & \\
\hline Blocks on websites/applications & & & & & & & & & & .17 & .11 & .08 & & \\
\hline
\end{tabular}

$* * p<.01 . * * * p<.001$. 
International Journal of Child, Youth and Family Studies (2020) 11(4.2): 13-36

An additional multivariate regression analysis was conducted to examine whether parental monitoring (parental restriction, parental solicitation, and youth disclosure) predicted the passivebystander role. The first model did not explain significant variance for this role $\left(R^{2}=.01, F(2,498)\right.$ $=2.72, p>.05)$. Neither the second model $\left(R^{2}=.02, \Delta R^{2}=.01, p>.05, F(5,495)=1.79, p>.05\right)$ nor the third model $\left(R^{2}=.03, \Delta R^{2}=.01, p>.05, F(8,492)=1.82, p>.05\right)$ significantly added to the predictive ability of the regression equation.

\section{The Interaction Effect of Parental Monitoring and Parent Gender (Which Parent Monitors/Which Parent Child Shares With) on Cyberbystander Roles (Aim 3)}

ANOVA analysis for the defender role was conducted based on the multivariate regression analyses in order to examine to what extent installing warning applications and sharing with parents differed by parent gender. Table 3 presents the average and standard deviation values of the main effects and interaction effects for cyberdefenders and cyberaggressors. Results show a significant main effect for sharing $\left(F(1,446)=7.64, p<.01, \eta^{2}=.02\right)$, such that adolescents who shared their online experiences with their parents $(M=2.51, S D=.95, n=240)$ defended the victim more than adolescents who did not share these experiences $(M=2.01, S D=.86, n=261)$. However, main effects were not found for warning applications $(F(1,446)=2.74, p>.05)$, which parent monitored $(F(3,446)=.64, p>.05)$, and with which parent the adolescent shared information $(F(3,446)=.53, p>.05)$; also, interaction effects were not found to be significant for the defender role. Table 3 presents the averages and standard deviations of the main effects and interaction effects for the cyberdefender role.

An additional ANOVA analysis was conducted for the aggressor-supporter role in order to examine the extent to which installing warning applications differed by parent gender. Results indicated a main effect for warning applications $\left(F(1,485)=48.26, p<.001, \eta^{2}=.09\right)$, such that higher aggressor-supporter scores were found among adolescents whose parents installed warning applications $(M=1.79, S D=1.08, n=56)$ compared to those whose parents did not install these applications $(M=1.18, S D=.44, n=445)$. A main effect was also found for participant gender $\left(F(1,485)=11.79, p<.01, \eta^{2}=.02\right)$, such that significantly more boys $(M=1.39, S D=.71, n=$ 171) than girls $(M=1.18, S D=.49, n=330)$ reported supporting the aggressor.

Three interaction effects significantly predicted the aggressor-supporter role: the first interaction effect between gender and gender of monitoring parent predicted the aggressorsupporter role $\left(F(3,485)=5.07, p<.01, \eta^{2}=.03\right)$; the second interaction effect between warning applications and gender of monitoring parent predicted the aggressor-supporter role $(F(3,485)=$ 4.08, $\left.p<.01, \eta^{2}=.03\right)$; and the third interaction effect between participant gender, warning applications, and gender of monitoring parent predicted the aggressor-supporter role $(F(3,485)=$ 4.02, $\left.p<.01, \eta^{2}=.02\right)$. 
International Journal of Child, Youth and Family Studies (2020) 11(4.2): 13-36

Table 3. Averages and Standard Deviations of the Main Effects and Interaction Effects for Cyberdefender and Cyberaggressor

\begin{tabular}{|c|c|c|c|c|c|}
\hline \multicolumn{6}{|c|}{ Defender } \\
\hline & Sharing & With which parent do you share? & $M$ & $S D$ & $n$ \\
\hline & \multirow[t]{5}{*}{ Yes } & Father & 2.35 & .83 & 16 \\
\hline & & Mother & 2.52 & .94 & 115 \\
\hline & & Both equally & 2.65 & .97 & 79 \\
\hline & & Neither & 2.20 & .96 & 30 \\
\hline & & Total & 2.51 & .95 & 240 \\
\hline & \multirow[t]{5}{*}{ No } & Father & 2.14 & .95 & 18 \\
\hline & & Mother & 2.08 & .90 & 79 \\
\hline & & Both equally & 2.24 & .89 & 48 \\
\hline & & Neither & 1.84 & .78 & 116 \\
\hline & & Total & 2.01 & .86 & 261 \\
\hline \multicolumn{6}{|c|}{ Aggressor-supporter } \\
\hline Gender & Warning applications & Which parent monitors? & $M$ & $S D$ & $n$ \\
\hline \multirow[t]{11}{*}{ Boys } & \multirow[t]{5}{*}{ Yes } & Father & 2.50 & 1.33 & 6 \\
\hline & & Mother & 1.87 & 1.29 & 13 \\
\hline & & Both equally & 1.74 & .74 & 9 \\
\hline & & Neither & 2.11 & .38 & 3 \\
\hline & & Total & 1.98 & 1.09 & 31 \\
\hline & \multirow[t]{5}{*}{ No } & Father & 1.33 & .64 & 15 \\
\hline & & Mother & 1.23 & .47 & 47 \\
\hline & & Both equally & 1.35 & .61 & 24 \\
\hline & & Neither & 1.22 & .48 & 54 \\
\hline & & Total & 1.26 & .51 & 140 \\
\hline & Total & & 1.39 & .71 & 171 \\
\hline \multirow[t]{11}{*}{ Girls } & \multirow[t]{5}{*}{ Yes } & Father & 1.00 & .00 & 3 \\
\hline & & Mother & 1.17 & 1.29 & 12 \\
\hline & & Both equally & 1.75 & .501 & 4 \\
\hline & & Neither & 2.44 & .41 & 6 \\
\hline & & Total & 1.55 & 1.04 & 25 \\
\hline & \multirow[t]{5}{*}{ No } & Father & 1.08 & .18 & 20 \\
\hline & & Mother & 1.15 & .38 & 107 \\
\hline & & Both equally & 1.23 & .49 & 53 \\
\hline & & Neither & 1.13 & .39 & 125 \\
\hline & & Total & 1.15 & .40 & 305 \\
\hline & Total & & 1.18 & .49 & 330 \\
\hline
\end{tabular}


Figure 1. Interaction Effect of Warning Applications and Which Parent Monitors on the Aggressor-Supporter Role for Boys

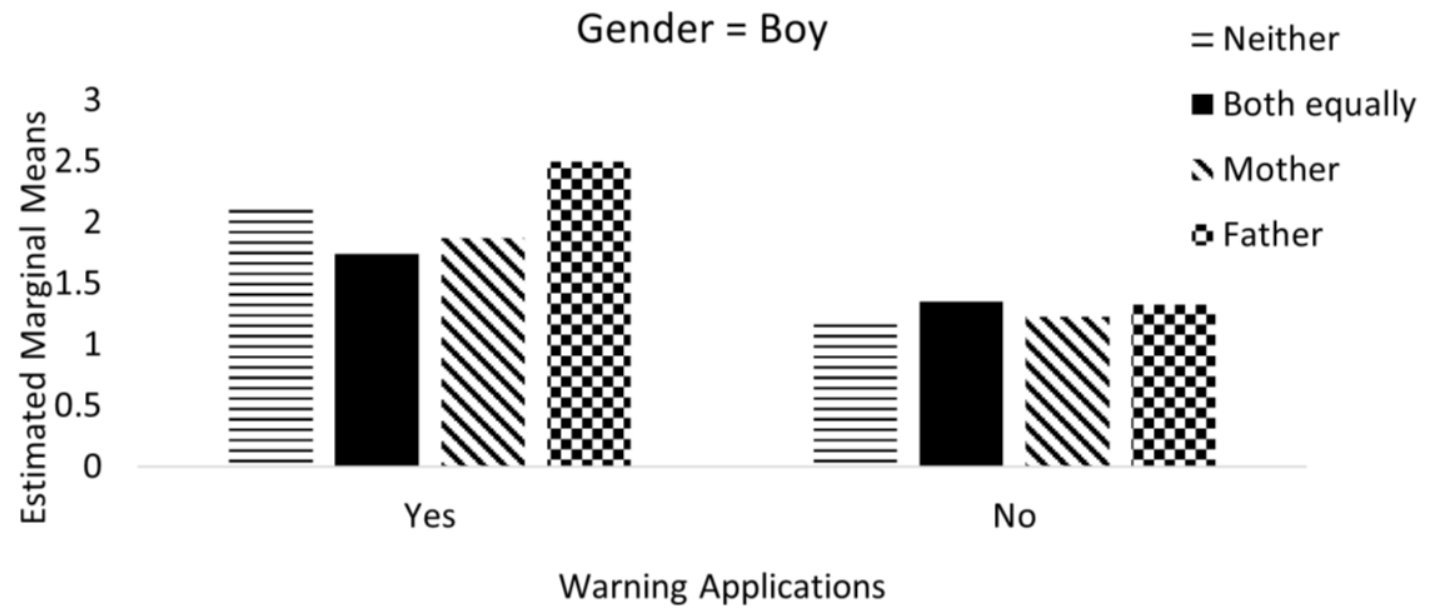

Figure 1 illustrates the three interactions and shows higher scores for the aggressor-supporter role among boys whose parents installed warning applications and whose fathers monitored their online activities $(M=2.50, S D=1.33, n=6)$. The lowest scores for this role were found among boys whose parents did not install warning applications and whose online activities were monitored by neither parent $(M=1.22, S D=.48, n=54)$. In contrast, Figure 2 shows higher aggressor-supporter role scores among girls whose parents installed warning applications but did not monitor their online activities $(M=2.44, S D=1.41, n=6)$, whereas the lowest scores for this role were found among girls whose parents did not install warning applications and whose fathers monitored their online activities $(M=1.08, S D=.18, n=20)$.

Figure 2. Interaction Effect of Warning Applications and Which Parent Monitors on the Aggressor-Supporter Role for Girls

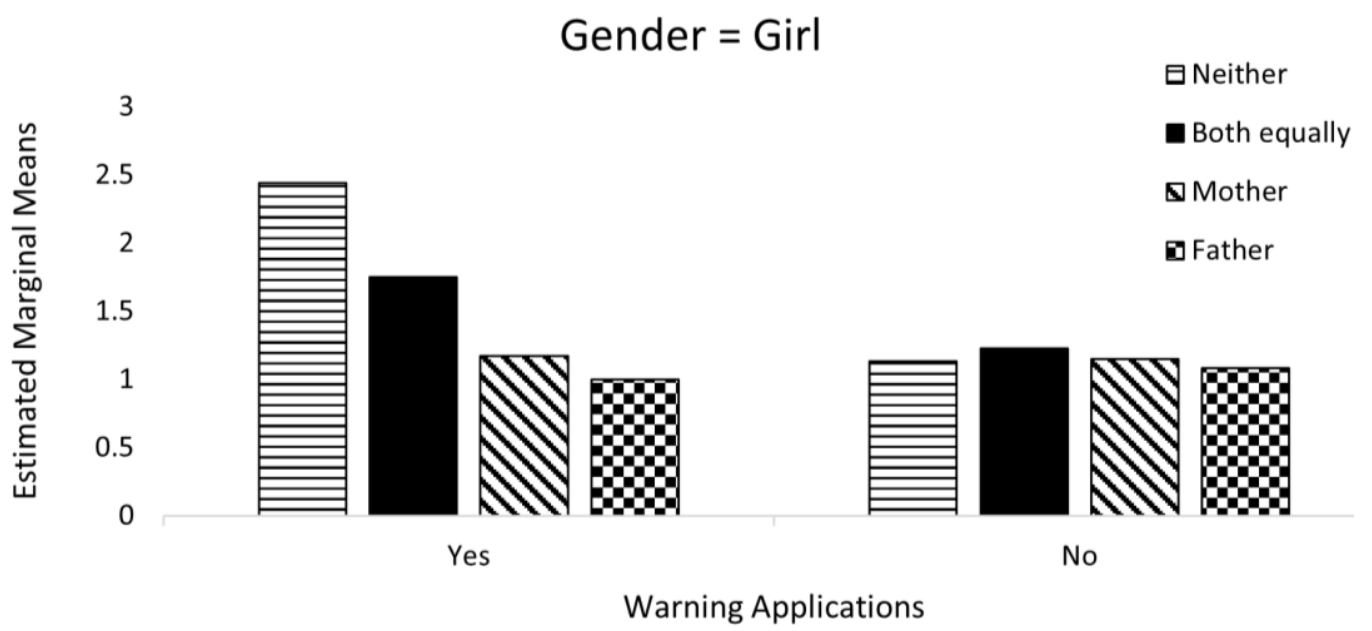


International Journal of Child, Youth and Family Studies (2020) 11(4.2): 13-36

\section{Discussion}

This paper presents the findings of a study that explored the effect of parental monitoring on cyberaggression bystander roles. The main purpose of the current study was to examine the effect of this mediation on cyberbystander roles by participant age and gender, and parent gender. Several findings are particularly noteworthy.

First, contrary to hypothesis H1, the help-seeker role was not found to be distinct from the defender role. This result may indicate that, unlike traditional aggression, cyberbystander provictim roles are not distinguished by direct (defender) and indirect (help-seeker) patterns (Levy \& Gumpel, 2018). This may be the result of the indirect nature of online interaction, which is characterized by anonymity, low supervision, and physical distance (Patchin \& Hinduja, 2010).

Furthermore, the analysis did not find an empirical distinction between the outsider and the passive-bystander roles, but instead showed that these two roles merge into one in online aggression. The item "You usually do not come across situations where cyberaggression occurs" was not associated with any of the cyberbystander roles. This may be explained by the unique characteristics of online interaction in which all participants are exposed to and aware of cyberaggression incidents. Therefore, both the passive bystander and the outsider exhibit passive behaviors and avoid active intervention. Previous studies suggested that although the outsider and the passive bystander exhibit similar behavior, they represent different roles. While the outsider was associated with the victim, the passive bystander was associated with the aggressor-supporter (Levy \& Gumpel, 2018). The current study may suggest that the outsider roles in cyberaggression and in traditional aggression are not the same. Therefore, assessment of this role in online aggression is inaccurate and further research should examine the distinctions between the outsider and passive-bystander roles in the cyberaggression context.

Second, the results support hypothesis H2 and reveal that youth disclosure (sharing with a parent) is key to cyberbystander roles. The results indicate that adolescents who shared their online cyberaggression experiences with their parents tended to defend the victim more than those who did not share. This result concurs with prior research showing youth disclosure to be a protective factor against both traditional aggression and cyberaggression (Elsaesser et al., 2017). Nonetheless, and contrary to hypothesis $\mathrm{H} 4$, an interaction effect was not found between sharing with a parent and the gender of the parent with which the information was shared. This may imply that youth disclosure is a key element in motivating teenagers to support the victim, regardless of which parent they share their cyberaggression involvement with. However, this result may differ by cyberaggression type. For example, girls who are bystanders to cybersexual aggression may confide in their mothers more than their fathers, because they prefer to discuss intimate gender issues with a member of their own gender. Hence, future studies should further explore this result with consideration of the different types of cyberaggression. 
Third, as proposed in hypothesis $\mathrm{H} 2$, adolescents who reported parental restriction (warning applications) were more likely to support the aggressor than those whose parents did not use restriction interventions. This finding is compatible with a previous study showing that adolescents whose parents used restriction interventions were more likely to be cyberaggressors and cyberaggression victims than those whose parents did not use such measures (Mishna et al., 2012). Hence, parental restriction measures in cyberaggression are more prevalent among cyberaggressors and aggressor-supporters.

Additionally, in agreement with hypothesis $\mathrm{H} 3$, only one parental solicitation practice predicted the aggressor-supporter bystander role: parental rule-setting for online behavior. The results indicate a positive association between rule-setting and the aggressor-supporter role, such that rules set by parents predicted the aggressor-supporter bystander role. Since rule-setting is considered another form of parental restriction (Kerr et al., 2010), these results may imply that parental restrictions (e.g., using technologies to block websites or applications, or setting rules) are more common among aggressor-supporters, perhaps as a consequence of their involvement in cyberaggression. These results raise questions regarding the efficacy of restriction interventions in discouraging adoption of the pro-aggressor bystander role. Perhaps these restrictive parental measures do not serve as a substitute for direct parental involvement in addressing adolescent cyberaggression by, for example, creating an atmosphere in which adolescents willingly share their cyberaggression experiences. Future studies should examine the reasons that parents restrict their children's online activity, especially in the case of cyberaggressor-supporters.

Fourth, the results of the current study highlight the role of parent gender in predicting the cyberbystander's role. Consistent with hypothesis H4, higher aggressor-supporter scores were found among boys whose parents installed warning applications and whose fathers monitored their online activities. However, contrary to H4, higher aggressor-supporter scores were found among girls whose parents installed warning applications, but neither parent monitored their online activities. Finally, the lowest aggressor-supporter scores were found among girls whose parents did not install warning applications and whose fathers monitored their online activities. These results point to the important role fathers play in their adolescent children's adopting the cyberbystander role. Paternal monitoring increases the likelihood of boys supporting the cyberaggressor, but decreases that likelihood among girls. These results contradict the finding of a previous study that mothers are more involved than fathers in monitoring their children's online use at home (Lau \& Yuen, 2016). However, that study did not specifically examine the effect of parental monitoring on cyberbystander roles.

Some scholars consider cyberaggression to be a form of indirect aggression (Hemphill et al., 2012), one that uses social relationships as a direct or indirect means of controlling and socially isolating the victim. This type of aggression has been reported to be more common among girls (Bjorkqvist et al., 1992; Crick et al., 2007). Many forms of relational aggression and cyberaggression are considered covert and not easily recognized by adults, and so are less frequently addressed by parents and school practitioners (Barnes et al., 2012). This may explain 
International Journal of Child, Youth and Family Studies (2020) 11(4.2): 13-36

why girls in our study tended to support the cyberaggressor when neither parent monitored their online activities.

Lastly, contrary to hypothesis $\mathrm{H} 4$, interaction effects between age and restriction interventions or sharing with a parent did not predict any of the bystander roles. This result is inconsistent with previous studies finding that bystander roles differ between early and later adolescence (OlenikShemesh et al., 2017; Pabian \& Vandebosch, 2016; Van Cleemput et al., 2014). However, this inconsistency may be the result of the relatively small number of young adolescents (in Grades 8 to 9) in the present sample.

Furthermore, parental monitoring measures, such as adolescent disclosure, installing warning applications, and blocking websites, were not associated with the passive-bystander role. This result raises questions regarding the extent and type of parental influence on certain cyberbystander roles, and highlights the stability of passive cyberaggression patterns in the face of family influences. Future studies should examine the effect of parental and other proximal and distal influences on the passive-cyberbystander role.

\section{Limitations}

The results of the current study may have been influenced by a relatively higher representation of girls and older adolescents. Additionally, the results regarding the outsider and passivebystander roles indicate that further analysis of the distinction between the two is needed. The abovementioned explanations regarding parent gender differences in online monitoring of both genders clearly indicate that further research is required.

\section{Implications for Practice}

The results of the current study highlight the importance of designing prevention programs that focus on both parental monitoring and adolescent disclosure. These programs should encourage adolescents to frequently engage in disclosure and share their cyberexperiences with their parents. Prevention programs should also aim to increase parents' awareness of the benefits of expanding their dialogues with adolescents on issues rather than relying on restriction interventions.

Another important implication is the need to design prevention programs aimed at developing the communication skills of both the parent and the adolescent in order to effectively contend with cyberaggression incidents. Such programs should focus on training parents and adolescents to recognize both cyberaggression and cybervictimization incidents and to practise effective coping and response strategies including defending the victim, sharing incidents with parents, and parental involvement and guidance. 
International Journal of Child, Youth and Family Studies (2020) 11(4.2): 13-36

\section{References}

Anderson, M., \& Jiang, J. (2018). Teens, social media \& technology. Pew Research Center. http://www.pewinternet.org/wpcontent/uploads/sites/9/2018/05/PI_2018.05.31_TeensTech_FINAL.pdf

Atlas, R. S., \& Pepler, D. J. (1998). Observations of bullying in the classroom. The Journal of Educational Research, 92(2), 86-99. doi:10.1080/00220679809597580

Baldry, A. C., Sorrentino, A., \& Farrington, D. P. (2019). Cyberbullying and cybervictimization versus parental supervision, monitoring and control of adolescents' online activities. Children and Youth Services Review, 96, 302-307. doi:10.1016/j.childyouth.2018.11.058

Bandalos, D. L., \& Finney, S. J. (2018). Factor analysis: Exploratory and confirmatory. In G. R. Hancock \& R. O. Mueller (Eds.), The reviewer's guide to quantitative methods in the social sciences (pp. 93-114). Routledge.

Barlińska, J., Szuster, A., \& Winiewski, M. (2013). Cyberbullying among adolescent bystanders: Role of the communication medium, form of violence, and empathy. Journal of Community \& Applied Social Psychology, 23(1), 37-51. doi:10.3389/fpsyg.2018.00799

Barnes, A., Cross, D., Lester, L., Hearn, L., Epstein, M., \& Monks, H. (2012). The invisibility of covert bullying among students: Challenges for school intervention. Journal of Psychologists and Counsellors in Schools, 22(2), 206-226. doi:10.1017/jgc.2012.27

Bastiaensens, S., Pabian, S., Vandebosch, H., Poels, K., Van Cleemput, K., DeSmet, A., \& De Bourdeaudhuij, I. (2016). From normative influence to social pressure: How relevant others affect whether bystanders join in cyberbullying. Social Development, 25(1), 193211.doi:10.1111/sode. 12134

Bastiaensens, S., Vandebosch, H., Poels, K., Van Cleemput, K., Desmet, A., \& De Bourdeaudhuij, I. (2014). Cyberbullying on social network sites. An experimental study into bystanders' behavioural intentions to help the victim or reinforce the bully. Computers in Human Behavior, 31, 259-271. doi:10.1016/j.chb.2013.10.036

Björkqvist, K., Lagerspetz, K. M. J., \& Kaukiainen, A. (1992). Do girls manipulate and boys fight? Developmental trends in regard to direct and indirect aggression. Aggressive behavior, 18(2), 117-127. doi:10.1002/1098-2337(1992)18:2<117

Boniel-Nissim, M., \& Sasson, H. (2018). Bullying victimization and poor relationships with parents as risk factors of problematic internet use in adolescence. Computers in Human Behavior, 88, 176-183. doi:10.1016/j.chb.2018.05.041

Bronfenbrenner, U. (1992). Ecological systems theory. In R. Vasta (Ed.), Six theories of child development: Revised formulations and current issues (pp. 187-249). Jessica Kingsley. 
International Journal of Child, Youth and Family Studies (2020) 11(4.2): 13-36

Crick, N. R., Ostrov, J. M., \& Kawabata, Y. (2007). Relational aggression and gender: An overview. In D. J. Flannery, A. T. Vazsonyi, \& I. D. Waldman (Eds.), The Cambridge handbook of violent behavior and aggression (pp. 245-259). Cambridge University Press. doi:10.1017/CBO9780511816840.012

DeSmet, A., Bastiaensens, S., Van Cleemput, K., Poels, K., Vandebosch, H., Cardon, G., \& De Bourdeaudhuij, I. (2016). Deciding whether to look after them, to like it, or leave it: A multidimensional analysis of predictors of positive and negative bystander behavior in cyberbullying among adolescents. Computers in Human Behavior, 57, 398-415. doi:10.1016/j.chb.2015.12.051

DeSmet, A., Veldeman, C., Poels, K., Bastiaensens, S., Van Cleemput, K., Vandebosch, H., \& De Bourdeaudhuij, I. (2014). Determinants of self-reported bystander behavior in cyberbullying incidents amongst adolescents. Cyberpsychology, Behavior, and Social Networking, 17(4), 207-215. doi:10.1089/cyber.2013.0027

Elsaesser, C., Russell, B., Ohannessian, C. M., \& Patton, D. (2017). Parenting in a digital age: A review of parents' role in preventing adolescent cyberbullying. Aggression and Violent Behavior, 35, 62-72.doi:10.1016/j.avb.2017.06.004

Frijns, T., Keijsers, L., \& Finkenauer, C. (2020). Keeping secrets from parents: On galloping horses, prancing ponies and pink unicorns. Current Opinion in Psychology, 31, 49-54. doi:10.1016/j.copsyc.2019.07.041

Grigg, D. W. (2010). Cyberaggression: Definition and concept of cyberbullying. Journal of Psychologists and Counsellors in Schools, 20(2), 143-156. doi:10.1375/ajgc.20.2.143

Hawkins, D. L., Pepler, D. J., \& Craig, W. M. (2001). Naturalistic observations of peer interventions in bullying. Social Development, 10(4), 512-527. doi:10.1111/1467-9507.00178

Hemphill, S. A., Kotevski, A., Tollit, M., Smith, R., Herrenkohl, T. I., Toumbourou, J. W., \& Catalano, R. F. (2012). Longitudinal predictors of cyber and traditional bullying perpetration in Australian secondary school students. Journal of Adolescent Health, 51(1), 59-65. doi:10.1016/j.jadohealth.2011.11.019

Hinduja, S., \& Patchin, J. W. (2010). Bullying, cyberbullying, and suicide. Archives of Suicide Research, 14(3), 206-221. doi:10.1080/13811118.2010.494133

Hong, J. S., \& Espelage, D. L. (2012). A review of research on bullying and peer victimization in school: An ecological system analysis. Aggression and Violent Behavior, 17(4), 311-322. doi:10.1016/j.avb.2012.03.003 
International Journal of Child, Youth and Family Studies (2020) 11(4.2): 13-36

Kazerooni, F., Taylor, S. H., Bazarova, N. N., \& Whitlock, J. (2018). Cyberbullying bystander intervention: The number of offenders and retweeting predict likelihood of helping a cyberbullying victim. Journal of Computer-Mediated Communication, 23(3), 146-162. doi:10.1093/jcmc/zmy005

Keijsers, L., \& Poulin, F. (2013). Developmental changes in parent-child communication throughout adolescence. Developmental Psychology, 49(12), 23012308. doi:10.1037/a0032217

Kerr, M., Stattin, H., \& Burk, W. J. (2010). A reinterpretation of parental monitoring in longitudinal perspective. Journal of Research on Adolescence, 20(1), 39-64. doi:10.1111/j.1532-7795.2009.00623.x

Khurana, A., Bleakley, A., Jordan, A. B., \& Romer, D. (2015). The protective effects of parental mediation and internet restriction on adolescents' risk of online harassment. Journal of Youth and Adolescence, 44(5), 1039-1047. doi:10.1007/s10964-014-0242-4

Kowalski, R. M., Giumetti, G. W., Schroeder, A. N., \& Lattanner, M. R. (2014). Bullying in the digital age: A critical review and meta-analysis of cyberbullying research among youth. Psychological Bulletin, 140(4), 1073-1137. doi:10.1037/a0035618

Laird, R. D., Marrero, M. D., Melching, J., \& Kuhn, E. S. (2013). Brief report: Improving the validity of assessments of adolescents' feelings of privacy invasion. Journal of Adolescence, 36(1), 227-231. doi:10.1016/j.adolescence.2012.10.011

Lau, W. W., \& Yuen, A. H. (2016). The relative importance of paternal and maternal parenting as predictors of adolescents' home internet use and usage. Computers \& Education, 102, 224233. doi:10.1016/j.compedu.2016.09.002

Levy, M., \& Gumpel, T. P. (2018). The interplay between bystanders' intervention styles: An examination of the "bullying circle" approach. Journal of School Violence, 17(3), 339-353. doi:10.1080/15388220.2017.1368396

Macháčková, H., Dedkova, L., Sevcikova, A., \& Cerna, A. (2013). Bystanders' support of cyberbullied schoolmates. Journal of Community \& Applied Social Psychology, 23, 25-36. doi:10.1002/casp.2135

Makri-Botsari, E., \& Karagianni, G. (2014). Cyberbullying in Greek adolescents: The role of parents. Procedia - Social and Behavioral Sciences, 116, 3241-3253. https://doi.org/10.1016/j.sbspro.2014.01.742

Mesch, G. S. (2009). Parental mediation, online activities, and cyberbullying. CyberPsychology \& Behavior, 12(4), 387-393. doi:10.1089/cpb.2009.0068 
International Journal of Child, Youth and Family Studies (2020) 11(4.2): 13-36

Mishna, F., Khoury-Kassabri, M., Gadalla, T., \& Daciuk, J. (2012). Risk factors for involvement in cyber bullying: Victims, bullies and bully-victims. Children and Youth Services Review, 34(1), 63-70. doi:10.1016/j.childyouth.2011.08.032

Modecki, K. L., Minchin, J., Harbaugh, A. G., Guerra, N. G., \& Runions, K. C. (2014). Bullying prevalence across contexts: A meta-analysis measuring cyber and traditional bullying. Journal of Adolescent Health, 55(5), 602-611. doi:10.1016/j.jadohealth.2014.06.007

Obermaier, M., Fawzi, N., \& Koch, T. (2016). Bystanding or standing by? How the number of bystanders affects the intention to intervene in cyberbullying. New Media \& Society, 18(8), 1491-1507. doi:10.1177/1461444814563519

Olenik-Shemesh, D., Heiman, T., \& Eden, S. (2017). Bystanders' behavior in cyberbullying episodes: Active and passive patterns in the context of personal-socio-emotional factors. Journal of Interpersonal Violence, 32(1), 23-48. doi:10.1177/0886260515585531

Pabian, S., \& Vandebosch, H. (2016). An investigation of short-term longitudinal associations between social anxiety and victimization and perpetration of traditional bullying and cyberbullying. Journal of Youth and Adolescence, 45(2), 328-339. doi:10.1007/s10964-015$\underline{0259-3}$

Patchin, J. W., \& Hinduja, S. (2010). Trends in online social networking: adolescent use of MySpace over time. New Media \& Society, 12(2), 197-216. doi:10.1177/1461444809341857

Patterson, L. J., Allan, A., \& Cross, D. (2017). Adolescent perceptions of bystanders' responses to cyberbullying. New Media \& Society, 19(3), 366-383. doi:10.1177/1461444815606369

Salmivalli, C. (2010). Bullying and the peer group: A review. Aggression and Violent Behavior, 15(2), 112-120. doi:10.1016/j.avb.2009.08.007

Salmivalli, C., \& Voeten, M. (2004). Connections between attitudes, group norms, and behaviour in bullying situations. International Journal of Behavioral Development, 28(3), 246-258. doi:10.1080/01650250344000488

Sengupta, A., \& Chaudhuri, A. (2011). Are social networking sites a source of online harassment for teens? Evidence from survey data. Children and Youth Services Review, 33(2), 284-290. doi:10.1016/j.childyouth.2010.09.011

Shapka, J. D., \& Law, D. M. (2013). Does one size fit all? Ethnic differences in parenting behaviors and motivations for adolescent engagement in cyberbullying. Journal of Youth and Adolescence, 42(5), 723-738. doi:10.1007/s10964-013-9928-2

Thornberg, R., \& Jungert, T. (2013). Bystander behavior in bullying situations: Basic moral sensitivity, moral disengagement and defender self-efficacy. Journal of Adolescence, 36(3), 475-483. doi:10.1016/j.adolescence.2013.02.003 
International Journal of Child, Youth and Family Studies (2020) 11(4.2): 13-36

Valcke, M., Bonte, S., De Wever, B., \& Rots, I. (2010). Internet parenting styles and the impact on internet use of primary school children. Computers \& Education, 55(2), 454-464. doi:10.1016/j.compedu.2010.02.009

Van Cleemput, K., Vandebosch, H., \& Pabian, S. (2014). Personal characteristics and contextual factors that determine "helping," "joining in," and "doing nothing" when witnessing cyberbullying. Aggressive Behavior, 40(5), 383-396. doi:10.1002/ab.21534

Vandebosch, H., Beirens, L., D’Haese, W., Wegge, D., \& Pabian, S. (2012). Police actions with regard to cyberbullying: The Belgian case. Psicothema, 24(4), 646-652.

Wang, J., Iannotti, R. J., \& Nansel, T. R. (2009). School bullying among adolescents in the United States: Physical, verbal, relational, and cyber. Journal of Adolescent Health, 45(4), 368-375.doi:10.1016/j.jadohealth.2009.03.021

Wang, J., Nansel, T. R., \& Iannotti, R. J. (2011). Cyber and traditional bullying: Differential association with depression. Journal of Adolescent Health, 48(4), 415-417. doi:10.1016/j.jadohealth.2010.07.012

Wang, R., Bianchi, S. M., \& Raley, S. B. (2005). Teenagers' internet use and family rules: A research note. Journal of Marriage and Family, 67(5), 1249-1258. doi:10.1111/j.1741$\underline{3737.2005 .00214 . x}$

Wright, M. F. (2017). Parental mediation, cyberbullying, and cybertrolling: The role of gender. Computers in Human Behavior, 71, 189-195. doi:10.1016/j.chb.2017.01.059

Wright, M. F., \& Wachs, S. (2018). Does parental mediation moderate the longitudinal association among bystanders and perpetrators and victims of cyberbullying? Social Sciences, 7(11), 231-240. doi:10.3390/socsci7110231

Zurcher, J. D., Holmgren, H. G., Coyne, S. M., Barlett, C. P., \& Yang, C. (2018). Parenting and cyberbullying across adolescence. Cyberpsychology, Behavior, and Social Networking, 21(5), 294-303. doi:10.1089/cyber.2017.0586 
International Journal of Child, Youth and Family Studies (2020) 11(4.2): 13-36

\section{Appendix 1 \\ Factor Analyses}

Table 4. Factor Loadings of Exploratory Factor Analysis (EFA) and Confirmatory Factor Analysis (CFA) for the Cyberbystander Roles Scale $(N=501)$

\begin{tabular}{|c|c|c|c|c|c|c|c|}
\hline \multirow[b]{2}{*}{ Item } & \multicolumn{4}{|c|}{ EFA } & \multicolumn{3}{|c|}{ CFA } \\
\hline & $\mathrm{DF}$ & AS & $\mathrm{PB}$ & Out & $\mathrm{DF}$ & AS & $\mathrm{PB}$ \\
\hline $\begin{array}{l}\text { You advised the victim what to do after } \\
\text { the cyberaggression }\end{array}$ & .75 & -.10 & .10 & .00 & .66 & & \\
\hline $\begin{array}{l}\text { You sent a message to the whole group } \\
\text { demanding that they stop the } \\
\text { aggression against the victim }\end{array}$ & .78 & .02 & -.06 & -.01 & .72 & & \\
\hline $\begin{array}{l}\text { You sent a personal message to the } \\
\text { offender to stop hurting the victim }\end{array}$ & .70 & .25 & -.09 & .07 & .69 & & \\
\hline $\begin{array}{l}\text { You sent messages to others asking } \\
\text { them to help the victim }\end{array}$ & .73 & .12 & -.00 & .07 & .69 & & \\
\hline $\begin{array}{l}\text { You notified an adult (parent, teacher, } \\
\text { principal, counselor) about the victim's } \\
\text { online abuse }\end{array}$ & .74 & .06 & .04 & -.11 & .67 & & \\
\hline $\begin{array}{l}\text { You notified a family member or close } \\
\text { friend of the victim }\end{array}$ & .70 & .25 & -.01 & .07 & .69 & & \\
\hline $\begin{array}{l}\text { After the event, you went with the } \\
\text { victim to get help }\end{array}$ & .79 & .10 & -.07 & .03 & .77 & & \\
\hline $\begin{array}{l}\text { You encouraged others to send abusive } \\
\text { messages to the victim }\end{array}$ & .12 & .84 & .06 & -.05 & & .85 & \\
\hline $\begin{array}{l}\text { You sent the offensive messages or } \\
\text { offensive images of the victim to other } \\
\text { social media networks }\end{array}$ & .14 & .86 & .10 & -.10 & & .86 & \\
\hline $\begin{array}{l}\text { You responded with laughter to the } \\
\text { insult (you sent comments like: "ha, } \\
\text { ha" or a laughing emoji) }\end{array}$ & .03 & .79 & .14 & .07 & & .67 & \\
\hline $\begin{array}{l}\text { You spread offensive messages or } \\
\text { images of the aggressor to avenge what } \\
\text { he did to the victim }\end{array}$ & .20 & .83 & .09 & -.02 & & & \\
\hline $\begin{array}{l}\text { You read the offensive messages sent } \\
\text { to the victim, but did not respond. }\end{array}$ & -.03 & .21 & .69 & .13 & & & .61 \\
\hline $\begin{array}{l}\text { You preferred to disconnect and not } \\
\text { follow what was happening }\end{array}$ & .00 & .15 & .69 & .07 & & & .55 \\
\hline $\begin{array}{l}\text { You ignored the offensive messages } \\
\text { that were sent to the victim. }\end{array}$ & -.03 & -.04 & .78 & -.07 & & & .50 \\
\hline $\begin{array}{l}\text { You usually do not encounter situations } \\
\text { where cyberaggression occurs. }\end{array}$ & .06 & -.09 & .12 & .97 & & & \\
\hline$\%$ Variance explained & 26.14 & 46.00 & 56.89 & 63.59 & & & \\
\hline Cronbach's alpha $(\alpha)$ & .87 & .86 & .56 & - & & & \\
\hline
\end{tabular}

Note. Factor loadings above .50 are in bold. DF = Defender; AS = Aggressor-supporter;

$\mathrm{PB}=$ Passive bystander; Out $=$ Outsider. 